\title{
Mechanical Properties and Microscopic Mechanism of Coral Sand-Cement Mortar
}

\author{
Luoxin Wang, ${ }^{1}$ Junshuai Mei $\mathbb{D}^{1},{ }^{1}$ Jing Wu $\mathbb{D},{ }^{1}$ Xingyang He, ${ }^{2}$ Hainan Li, ${ }^{1}$ and Qingjun Ding ${ }^{3}$ \\ ${ }^{1}$ College of Materials Science and Engineering, Key Laboratory of Textile Fiber and Products, \\ Ministry of Education, Wuhan Textile University, Wuhan 430073, China \\ ${ }^{2}$ School of Civil Engineering and Architecture, Building Waterproof Engineering and \\ Technology Research Center of Hubei Province, Hubei University of Technology, Wuhan 430068, China \\ ${ }^{3}$ State Key Laboratory for Silicate Building Materials, Wuhan University of Technology, Wuhan 430070, China \\ Correspondence should be addressed to Jing Wu; wujing313@whut.edu.cn
}

Received 29 October 2019; Revised 25 December 2019; Accepted 3 January 2020; Published 24 February 2020

Academic Editor: Dora Foti

Copyright ( 2020 Luoxin Wang et al. This is an open access article distributed under the Creative Commons Attribution License, which permits unrestricted use, distribution, and reproduction in any medium, provided the original work is properly cited.

The workability and mechanical performance of coral sand-cement mortar (coral mortar, for short) and the modification effects of mineral admixtures on the coral mortar were studied in this paper. The results showed that the strength of coral mortar was lower than that of standard mortar, but the strength of coral mortar was improved by compositing with the mineral admixture, which can be attributed to the improvement of the microstructure and interface transition area. Scanning electron microscopy (SEM), energy dispersive X-ray spectroscopy (EDS), X-ray diffraction (XRD), and Fourier transform infrared spectroscopy (FTIR) were used to explore the microscopic mechanism involved in the mechanical properties, volume stability, and hydration of mortar. The analyses revealed that the internal curing effect of coral sand improved the mechanical properties of mortar and its ability to resist shrinkage. The uneven surface of coral sand formed a meshing state of close combination with the hardened cement mortar, which helped to improve the volume stability of mortar. The $\mathrm{Ca}^{2+}$ and $\mathrm{Mg}^{2+}$ ions from coral sand participated in the hydration reaction of cement, which contributed to generating more hydration products. Moreover, the microaggregate filling and pozzolanic effects of fly ash and slag improved the mechanical properties of coral mortar and resistance to chloride ion diffusion.

\section{Introduction}

Sand and stone resources are important raw materials for national infrastructure construction. In recent years, with the depletion of natural river sand in China, the substitute aggregate of natural sand has attracted extensive attention from academic and engineering scholars. The mining of manufactured sand can alleviate the shortage of natural river sand to some extent, but large amounts of energy will be consumed due to the crushing of manufactured sand $[1,2]$. Moreover, the destruction of the mountain structure, dust pollution, and debris flow problems are derived from overexploitation of manufactured sand $[1,3]$, and the transportation is still difficult for the islands and coastal areas [4]. Therefore, in order to prevent destruction of the local ecological environment, crushed coral bones on islands are used to prepare concrete instead of river sand $[5,6]$. This has important practical significance for island engineering construction.

Since the Second World War, coral sand has been used in many modern military and civilian marine construction projects [7-9]. In the Pacific Rim, the coral island engineering has developed rapidly. Due to the convenience of exploitation, coral sand is widely used in the construction of islands, breakwater roads, and airports in coastal areas [10-12]. Compared with standard mortar, coral mortar has better volume stability. Coral sand has the property of continuously releasing calcite into mortar $[13,14]$. Calcite filled in the interfacial transition zone of coral mortar helps to improve the compactness of the mortar [15], which can enhance the mechanical properties and resistance to shrinkage of the mortar. Fly ash and slag have good pozzolanic activity, filling effect, and chloride ion-immobilizing effect. Thus, the coral mortar incorporated with fly ash and slag has better 
mechanical properties and resistance to chloride penetration. Howdyshell et al. investigated the feasibility of using coral sand for concrete and found that coral sand has an uneven surface and porous structure with high water absorption capacity [16], which can increase the strength of concrete. In addition, compared to ordinary standard mortar, the interface transition zone of coral mortar is more compact $[17,18]$. However, due to the unreliable sources of coral sand and its unstable composition and gradation, the experimental results of coral mortar vary greatly, and the parallel comparison between different literature reports also lacks theoretical support. Therefore, the mortar prepared by high-quality coral sand with strict control of the composition and particle grading was studied herein, and its working performance, mechanical performance, volume stability, and microscopic performance were also compared with those of standard mortar. The influence of mineral admixtures on the coral mortar properties was also researched in this paper. The obtained results can provide a theoretical reference for designing the suitable composition of coral mortar.

\section{Experiment}

2.1. Raw Materials. Ordinary Portland cement (OPC) CEM I 42.5 with a density of $3.13 \mathrm{~g} / \mathrm{cm}^{3}$ and a surface area of $350 \mathrm{~m}^{2} / \mathrm{kg}$ was used in this study. The fly ash (FA) used in mortar passed through a $0.045 \mathrm{~mm}$ mesh screen, the weight of the screen residue was $7.8 \%$, the burning loss was $2.3 \%$, and the water demand ratio was $97 \%$. The activity index, density, and specific surface area of the slag (SG) used in mortar were $S 95,2.86 \mathrm{~g} / \mathrm{cm}^{3}$, and $4200 \mathrm{~cm}^{2} / \mathrm{g}$, respectively. The chemical composition of cementing materials is shown in Table 1. Coral sand was obtained from the crushed coral bone, with a porosity of $41.3 \%$ [14]. The grain size distribution is shown in Table 2. The fineness modulus of standard sand used here was $2.5 \mathrm{~mm}$, and its maximum diameter was $5 \mathrm{~mm}$. Figure 1 shows the morphology of aggregate particles. The liquefied SDS- (sodium dodecyl sulfate-) type polycarboxylate superplasticizer with a solid content of $10 \%$ was admixed to reduce the specific volume of water.

\subsection{Test Procedure}

2.2.1. Sample Preparation and Fluidity Test. The mixing proportions of mortar are shown in Table 3, where the watercement ratio was 0.4 and the binder-sand ratio was 0.5 . The binder materials and sand were added to the mixer in turn and mixed evenly. Then, water was added gradually, not exceeding $2 \mathrm{~min}$. After adding all the water, the mixing was continued for $2 \mathrm{~min}$. Then, the mixed mortar was placed into the truncated cone mold in two layers. The height of the first layer in the truncated cone mold was about two-thirds, and then it was pressed from the edge to the center 15 times with tamp. Then, as much as possible amount of mortar was placed into the mold again and pressed with tamp from the edge to the center 10 times. A knife was used to scrape off the excess mortar, and the top of the truncated cone mold was flattened. The mold was removed, and the jump table was started and vibrated 25 times. According to the ISO method
"Methods of testing cements-determination of strength," three samples were prepared in each group. Then, the three kinds of samples were molded in steel molds with a size of $40 \mathrm{~mm} \times 40 \mathrm{~mm} \times 160 \mathrm{~mm}$. The mortar samples were cured to the specified time under the standard curing environment, and then their mechanical properties, volume stability, and microscopic properties were tested.

A fluidity apparatus was used to test the flow performance of the mortar. The distance of the vibrating part from the table was $(10 \pm 0.2) \mathrm{mm}$, and the truncated cone mold was used for determining the fluidity of cement mortar. The upper mouth caliber was $(70 \pm 0.5) \mathrm{mm}$, the lower mouth caliber was $(100 \pm 0.5) \mathrm{mm}$, and the height was $(60 \pm 0.5)$ $\mathrm{mm}$. The experimental vibration frequency was $1 \mathrm{~Hz}$, and the vibration period was 25 times.

For the FTIR test, the mortar samples cured to specified time were ground by agate mortar until they passed through a 200 mesh size sieve. Then, 1-2 g powders were mixed with 100-200 g potassium bromide and continuously ground until well blended. Finally, transparent slices were obtained by pressing with a pressure of $8000-15000 \mathrm{~kg} / \mathrm{cm}^{2}$ for $1 \mathrm{~min}$ by an oil press. For preparing SEM samples, small fragments obtained from the middle part of mortar samples at a certain age were kept in acetone solution for 3 days (abbreviated as " $\mathrm{d}$ " in figures and tables below) and then were dried at $80^{\circ} \mathrm{C}$ for $8 \mathrm{~h}$. The XRD samples were prepared as follows: the samples were taken out at 28 days and their hydration was stopped. Then, they were dried in an oven for $4 \mathrm{~h}$ at $60^{\circ} \mathrm{C}$. Finally, the middle parts of the samples were taken, ground in an agate mortar, and passed through a 100 mesh size sieve.

2.2.2. Determination of Free and Immobilized Chloride Ion Contents in Mortar. As seawater contains a large amount of chloride ions, the coral aggregate used in constructions also contains a certain amount of chloride ions. To determine the chloride ion content in mortar, the contents of free chlorine ions and immobilized chlorine ions in coral mortar and FASG coral mortar were compared. Hardened coral mortar was ground until it passed through a 100 mesh size sieve. Then, six coral mortar samples with the same ratio were divided into one group, and the weight of each sample was $30 \mathrm{~g}$. Three samples of each group were soaked in distilled water for $24 \mathrm{~h}$ and shaken several times every hour during the $24 \mathrm{~h}$ so that the chlorine salt in the mortar was fully soaked out. The other three groups were soaked in $0.5 \mathrm{~mol} / \mathrm{L}$ nitric acid solution and then maintained at $105 \sim 110^{\circ} \mathrm{C}$ for $4 \sim 6 \mathrm{~h}$ to fully dissolve the immobilized chlorine salt in the mortar. Then, the solution was filtered through a vacuum filter box. The filtrate was retained, and the $\mathrm{pH}$ of the filtrate was adjusted to $7 \sim 8 . \mathrm{AgNO}_{3}$ solution with the predetermined concentration was used for titration, and $\mathrm{K}_{2} \mathrm{CrO}_{4}$ solution (5 wt.\%) was used as the final color indicator. According to the quantity of consumption of $\mathrm{AgNO}_{3}$ solution, the contents of free chlorine ions $\left(M_{0}\right)$ and total chloride ions $\left(M_{t}\right)$ of hardened coral mortar were calculated. Then, the chloride ion-immobilizing rate $(L)$ of mortar can be calculated by the following formula: 
TABLe 1: Chemical composition of cementing materials (wt.\%).

\begin{tabular}{lcccccccccc}
\hline Chemical analysis & $\mathrm{SiO}_{2}$ & $\mathrm{Al}_{2} \mathrm{O}_{3}$ & $\mathrm{Fe}_{2} \mathrm{O}_{3}$ & $\mathrm{CaO}$ & $\mathrm{MgO}$ & $\mathrm{K}_{2} \mathrm{O}$ & $\mathrm{Na}_{2} \mathrm{O}$ & $\mathrm{TiO}_{2}$ & $\mathrm{SO}_{3}$ & Ignition loss \\
\hline Cement & 21.99 & 5.92 & 3.26 & 58.64 & 1.98 & 0.74 & 0.27 & 0.4 & 2.6 & 3.5 \\
FA & 50.93 & 33.51 & 3.33 & 3.69 & 0.66 & 1.49 & 0.5 & 1.60 & 0.51 & 2.3 \\
SG & 29.89 & 16.20 & 0.41 & 35.53 & 10.96 & 0.36 & 0.45 & 1.27 & 3.32 & 0.37 \\
\hline
\end{tabular}

TABLE 2: Grain grading of coral sand (wt.\%).

\begin{tabular}{|c|c|c|c|c|c|c|c|}
\hline Mesh sieve $(\mathrm{mm})$ & 4.75 & 2.36 & 1.18 & 0.6 & 0.3 & 0.15 & $<0.15$ \\
\hline Surplus $(\mathrm{g})$ & 0 & 48.5 & 1418.7 & 506.6 & 413.9 & 100.7 & 2.9 \\
\hline Weight of the mesh residue (\%) & 0 & 1.95 & 56.95 & 20.33 & 16.61 & 4.04 & 0.12 \\
\hline Accumulated retained percentage & 0 & 1.95 & 58.9 & 79.23 & 95.84 & 99.88 & 100 \\
\hline
\end{tabular}
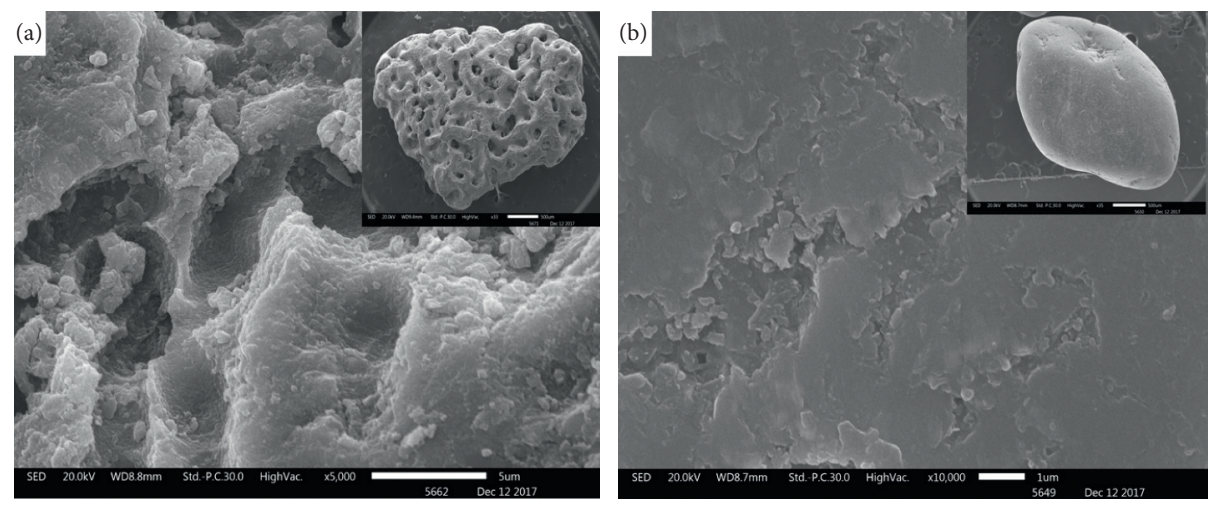

FIgURE 1: SEM images of the mortar aggregate. (a) Crushed coral sand. (b) Standard sand.

TABLe 3: Mix proportions of mortar samples (g).

\begin{tabular}{lccccccc}
\hline No. & Cement & Fly ash & Slag & Standard sand & Coral sand & Water & Admixture \\
\hline CSS & 600 & 0 & 0 & 1200 & 0 & 270 & 5 \\
CCS & 600 & 0 & 0 & 0 & 0 & 1200 & 270 \\
CFSCS & 420 & 90 & 90 & 000 & 270 \\
\hline
\end{tabular}

CSS: standard mortar; CCS: coral mortar; CFSCS: coral mortar with $15 \%$ fly ash and $15 \%$ slag.

$$
L=\frac{\left(M_{\mathrm{t}}-M_{0}\right)}{M_{\mathrm{t}}} .
$$

2.2.3. Test of Expansion Rate of Mortar Samples. The samples were molded in steel molds with a size of $20 \mathrm{~mm} \times 20 \mathrm{~mm} \times 280 \mathrm{~mm}$. Then, according to the JGJ/T702009 method "Standard for test method of performance building mortar," they were used to test the volume change [19]. After curing for $24 \mathrm{~h}$, the initial length of samples $L_{0}$ was measured with a comparator $(\mathrm{mm})$. Then, the samples were placed in a standard curing environment, and their length $L_{\mathrm{t}}(\mathrm{mm})$ was measured at regular intervals. The volume change rate $\left(\varepsilon=\left(L_{t}-L_{0}\right) / L_{0}\right)$ of samples at the corresponding age was calculated, and finally, the average result was calculated.

2.2.4. Electrochemical Property Testing of Mortar. Three groups of mortar samples were used with the size of $20 \mathrm{~mm} \times 20 \mathrm{~mm} \times 280 \mathrm{~mm}$. The samples were placed in a standard curing environment before the test. The sine voltage signal amplitude of the AC impedance tester is $5 \mathrm{~mA}$, the $\mathrm{AC}$ amplitude is $0.01 \mathrm{~V}$, and the measurement frequency range is $100 \mathrm{MHz}-10 \mathrm{kHz}$. Then, the mortar samples at 180 days were selected which kept the surface dry before the test. Cement-based materials can be regarded as comprising series of connected holes, nonconnected holes, and insulators (composed of aggregates and gel hydration products). The Nyquist plot of high-frequency AC impedance tests is shown in Figure 2 [20]. The intersection point on the left side of the semicircle with the solid line is the resistance of pore solution, marked $R_{0}$ [21-23], and the diameter of the semicircle corresponds to the resistance of gel hydration products, marked $R_{1}$.

\section{Results and Discussion}

3.1. Fluidity of Mortar Samples. Table 4 and Figure 3 show that coral mortar with fly ash and slag (FA-SG coral mortar, for short) had the worst fluidity, and the fluidity of coral mortar was worse than that of standard mortar. This is 


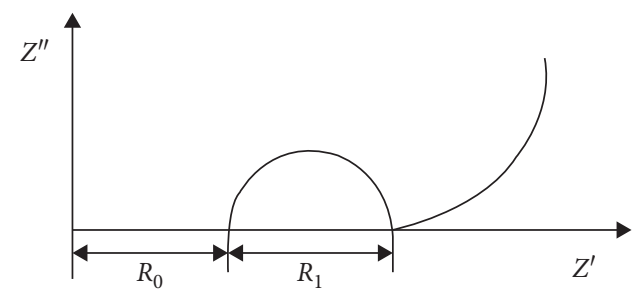

FIGURe 2: Nyquist plot of Randles type. $R_{0}$ is the resistance of pore solution, and $R_{1}$ is the resistance of gel hydration products.

TABLE 4: Fluidity and density of mortar samples.

\begin{tabular}{lccc}
\hline Mortar sample & CSS & CCS & CFSCS \\
\hline Diameter of mortar after vibration $(\mathrm{cm})$ & $25.4 \pm 0.1$ & $21.6 \pm 0.1$ & $17.1 \pm 0.3$ \\
Density $\left(\mathrm{kg} \cdot \mathrm{m}^{-3}\right)$ & 2256.64 & 2258.33 & 2280.73 \\
\hline
\end{tabular}

CSS: standard mortar; CCS: coral mortar; CFSCS: coral mortar with 15\% fly ash and 15\% slag.

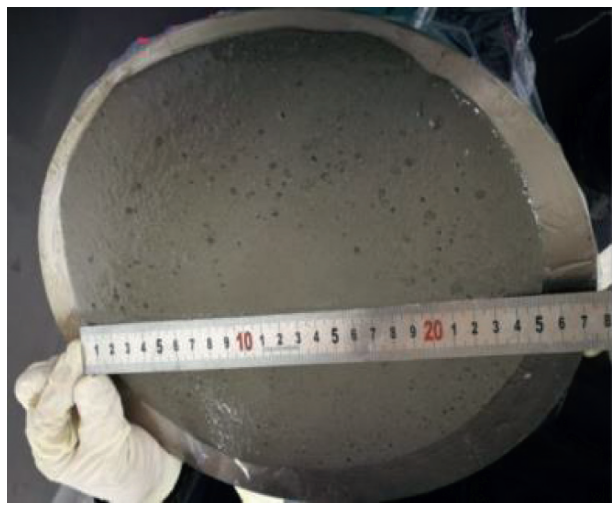

(a)

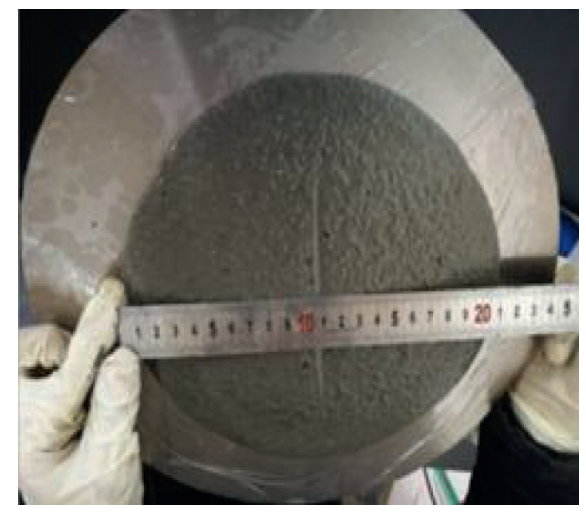

(b)

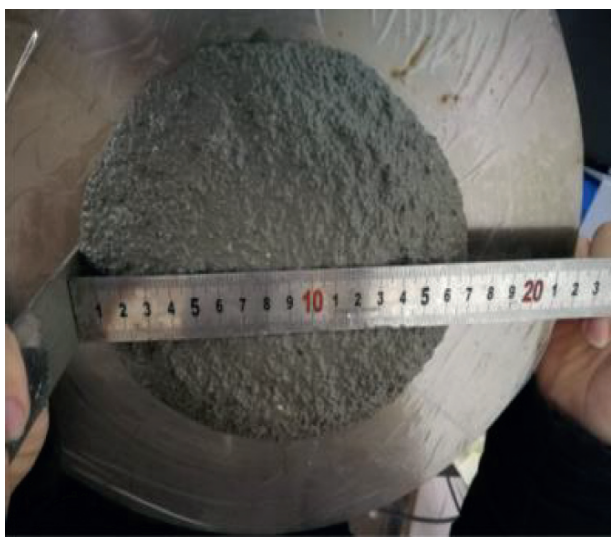

(c)

Figure 3: Fluidity test of mortar samples: (a) standard mortar; (b) coral mortar; (c) coral mortar with $15 \%$ fly ash and $15 \%$ slag.

because there are many crushed coral bones and shells in the coral sand and their porous structure can absorb a lot of water, thus lowering the fluidity of coral mortar. Moreover, due to the large specific surface area of fly ash and slag, a large amount of water was further adsorbed, thus causing the FA-SG coral mortar to have the lowest fluidity. The densities of standard mortar and coral mortar were similar, while the density of FA-SG coral mortar was higher than that of the other samples. This was likely due to the microaggregate filling effect of fly ash and slag particles.

3.2. Analysis of Volume Stability of Mortar Samples. Figure 4 shows the volume change rate with time for two groups of mortar samples. The volume change rate can be roughly divided into three stages. The first stage was the 


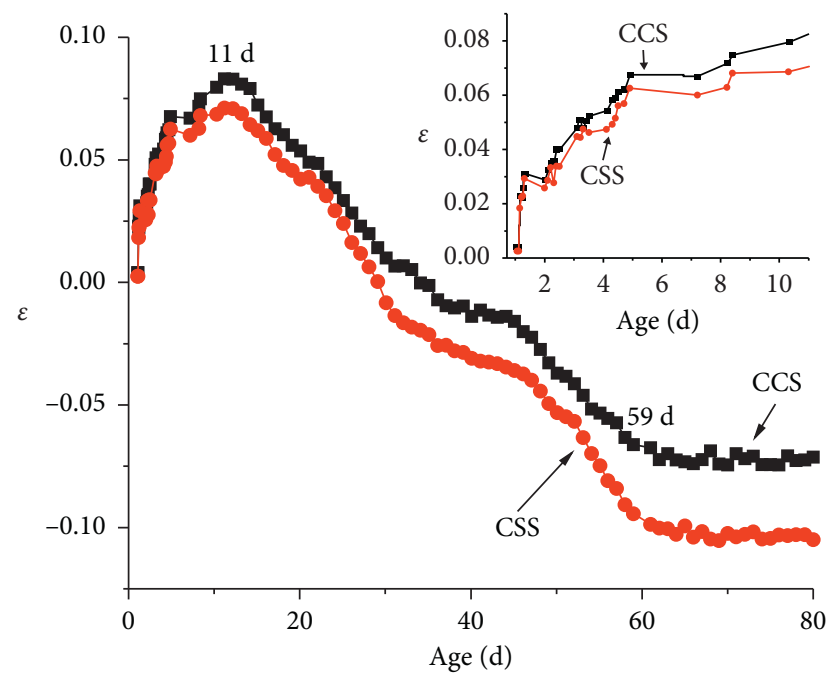

FIgURE 4: (a) Volume expansion rate of CSS (standard mortar) and CCS (coral mortar). (b) Section of the curve in (a) from 1 to $11 \mathrm{~d}$.

volume expansion period of mortar during 1 11 days. Especially during the first 7 days, the volume expansion of both mortar samples was very obvious. In addition, the volume change of coral mortar was more obvious at this stage due to the additional hydration reaction of $\mathrm{Mg}^{2+}$ and $\mathrm{SO}_{4}{ }^{2-}$ introduced from coral sand $[24,25]$. The second stage was the volume shrinkage period of mortar during 11 59 days. At this stage, the volume of mortar did not expand and started to contract significantly. The last stage was the stable volume period of mortar after 59 days. It can be seen from Figure 4 that the shrinkage value of coral mortar was lower than that of standard mortar, indicating that coral mortar was superior to standard mortar in volume stability. This is because the uneven surface of coral sand makes the interfacial transition zone between coral sand and hardened cement matrix more compact, resulting in better interface strength of coral mortar compared to standard mortar. In addition, coral sand, as a kind of porous aggregate, played an internal curing role of water storage and water release during the hydration stage of cement-based materials. This can maintain the relative humidity inside the mortar, ensure the continuous hydration of cement, and inhibit the drying shrinkage. Moreover, the unstable $\mathrm{CaCO}_{3}$ in coral sand was continuously released outward $[13,14]$ and precipitated in the form of calcite into the interface transition area. This helped to improve the compactness of the interface area and limited the volume shrinkage of coral mortar in the later stage.

3.3. Electrochemical Impedance Analysis. Using the Nyquist plot of Randles type in Figure 2, it can be seen from Figure 5 that, among the three resistance values $R_{0}$ of the pore solution of mortar samples, coral mortar had the smallest value, followed by standard mortar, and FA-SG coral mortar had the largest value, which was mainly due to numerous porous coral bones and shellfish in the coral sand. As a result, the total pore volume of coral mortar was more than

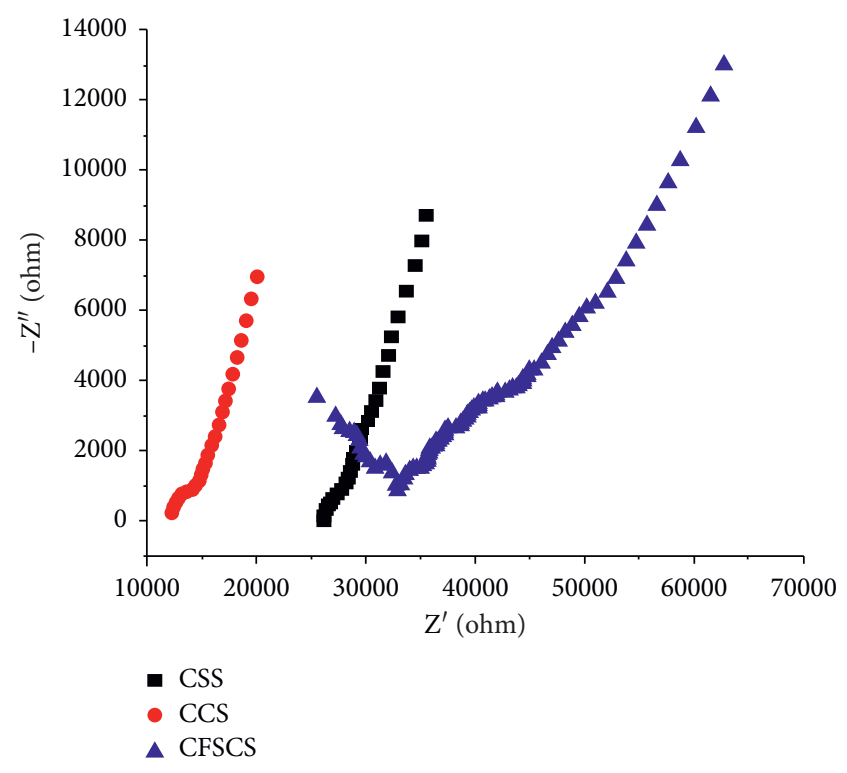

FIgURE 5: Impedance spectra of mortar samples at $180 \mathrm{~d}$. CSS: standard mortar; CCS: coral mortar; CFSCS: coral mortar with $15 \%$ fly ash and $15 \%$ slag.

that of standard mortar. In addition, more $\mathrm{Cl}^{-}$and $\mathrm{Mg}^{2-}$ ions were introduced into the pore solution of mortar because the pores of coral sand were connected with the pore network of the mortar matrix. Therefore, the pore solution resistance $R_{0}$ of coral mortar was significantly lower than that of standard mortar. In addition, the microaggregate filling and pozzolanic effects of fly ash and slag made the mortar denser and limited the migration of pore solution in the mortar. As a result, the pore solution resistance $R_{0}$ of FASG coral mortar was the highest. The resistance value $R_{1}$ of FA-SG coral mortar was significantly higher than that of the other two kinds of mortar samples possibly because the fine fly ash and slag particles promoted the hydration of cement.

3.4. Mechanical Property Test of Mortar. As shown in Figure 6, the compressive and flexural strengths of standard mortar at $7 \mathrm{~d}$ were the highest. When coral sand was used instead of standard sand, the flexural and compressive strengths of mortar decreased by $26.92 \%$ and $3.43 \%$, respectively. When modified by mineral admixtures, the flexural and compressive strengths of coral mortar were improved but were still below the corresponding values of standard mortar. This was due to the filling effect of fly ash $[26,27]$, which made the mortar structure denser. In addition, the pozzolanic reaction of fly ash and slag consumed a large amount of $\mathrm{Ca}(\mathrm{OH})_{2}$ in the interface transition zone of mortar and generated more C-S-H gel [28]. Consequently, the flexural and compressive strengths of FA-SG coral mortar were greater than those of coral mortar. However, due to the slow pozzolanic reaction rate, and a large amount of broken coral bones, shellfish, and other components that were not beneficial to the strength of mortar, the flexural and compressive strengths of FA-SG coral mortar at $7 \mathrm{~d}$ were still lower than those of standard 


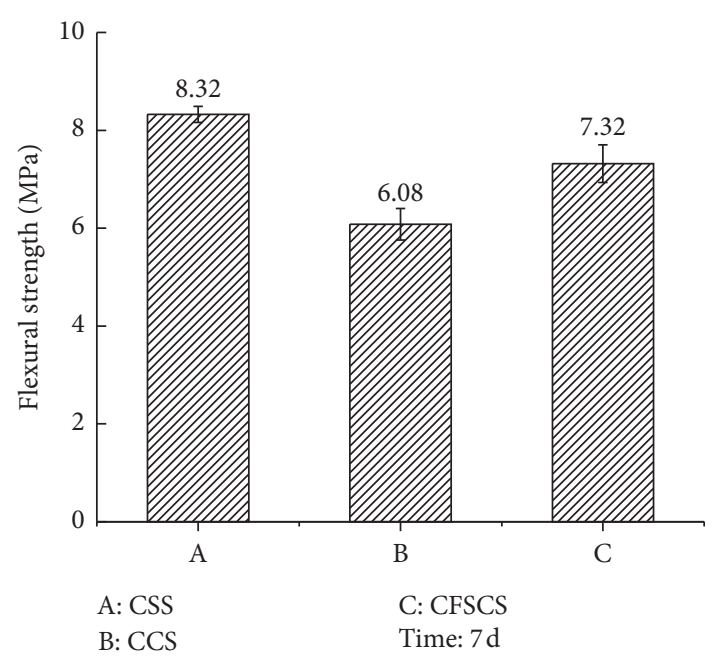

(a)

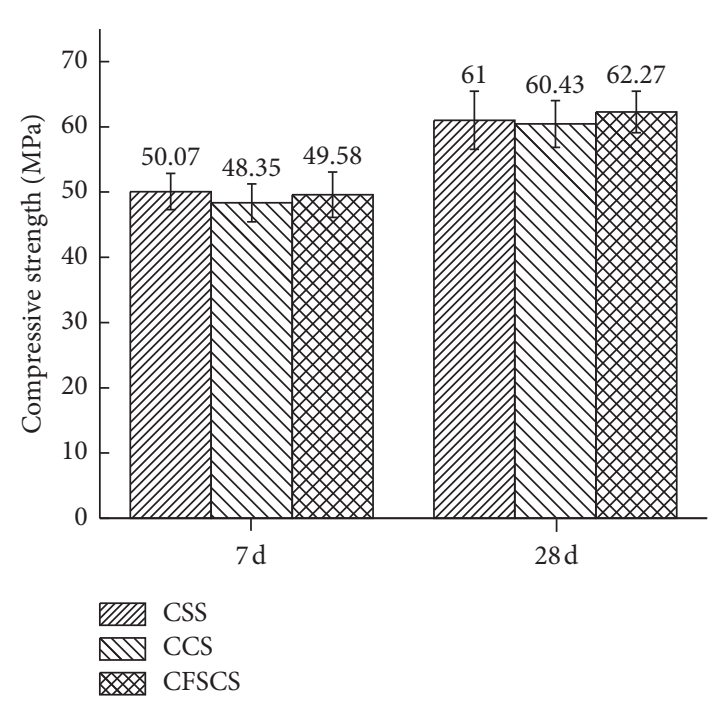

(b)

Figure 6: Flexural (a) and compressive (b) strengths of mortar samples at $7 \mathrm{~d}$ and $28 \mathrm{~d}$. CSS: standard mortar; CCS: coral mortar; CFSCS: coral mortar with $15 \%$ fly ash and $15 \%$ slag.

mortar. At $28 \mathrm{~d}$, the compressive strength of coral mortar was still lower than that of standard mortar, but the compressive strength of FA-SG coral mortar was $2.08 \%$ higher than that of standard mortar. This was due to the filling effect and the continuous pozzolanic reaction of the additional mineral admixture.

\subsection{Detection and Analysis of the Chloride Ion Content in} Mortar. In this paper, high-quality coral mortar was obtained by adding the mineral admixture to enhance the penetration resistance of chloride ions. As shown in Table 5, the chloride ion contents of coral mortar samples soaked in deionized water (DI-W) and nitric acid solution (H-S) were compared. The results show that FA-SG coral mortar contained less free chlorine ions. It is known that chloride ions react with calcium sulfoaluminate, the hydration product of cement mineral clinker $\mathrm{C} 3 \mathrm{~A}$, to form low-soluble calcium monoaluminate (Friedel's salt). Nevertheless, it has been demonstrated that the immobilizing ability of chloride ions of ordinary Portland cement mortar mainly depends on the content of C-S-H gel of the hydration product and is not related to the water-cement ratio and the aggregate characteristics [29]. Therefore, for FA-SG coral mortar, the pozzolanic reaction of mineral admixtures promoted the hydration of cement to generate more C-S-H gel, which further improved the ability of mortar to immobilize chloride ions. In addition, the porous structure of fly ash $[30,31]$ and its internal space connected with the pore network of mortar can increase the physical adsorption of chloride ions. Slag contains high $\mathrm{Al}_{2} \mathrm{O}_{3}$ mineral content, which can absorb chloride ions in mortar to generate Friedel's salt in the process of cement hydration. The chloride ion-immobilizing rate $(L)$ of mortar can be calculated by formula (1).
3.6. SEM and EDS Analyses. The micromorphology of the mortar is shown in Figure 7. The mortar matrix around the coral sand particles was selected as the scanning area for SEM. EDS was used to detect the content of elements in the interface transition zone (ITZ) near the sand particles and the matrix position (CM) far away from the sand particles. The detailed EDS results are shown in Figures 8 and 9 and Tables 6 and 7.

As shown in Figure 7, the structures of standard mortar and coral mortar at $7 \mathrm{~d}$ were loose, while the structure of FASG coral mortar was relatively denser. The hydration products of FA-SG coral mortar and standard mortar at $28 \mathrm{~d}$ were dense gel particles. No $\mathrm{Ca}(\mathrm{OH})_{2}$ flakes were found in FA-SG coral mortar samples, while coral mortar contained a large amount of $\mathrm{Ca}(\mathrm{OH})_{2}$ flakes. This is because the pozzolanic reaction consumed a lot of $\mathrm{Ca}(\mathrm{OH})_{2}$. In addition, the main chemical component of coral sand was $\mathrm{CaCO}_{3}$, existing in the form of microcrystalline calcite. Also, coral sand has the property of continuously releasing calcium carbonate in coral mortar. Therefore, in the SEM image of coral mortar at $28 \mathrm{~d}$, a large number of calcite hexagonal diamond crystals appeared in the interface transition zone [14]. These crystals were filled in the pores and cracks of cement paste and helped to improve the compactness and strength of the interface transition zone.

The results of EDS analysis in Tables 6 and 7 show that chloride ions in coral mortar permeated from the surface of coral sand to the inside of cement gel. The results of both samples showed that the chloride content of coral mortar decreased gradually from the interface transition zone (ITZ) near the sand particles to the matrix position (CM) far away from the sand particles. Moreover, according to the chloride ion content data in the far and near regions from sand particles in the coral mortar at $28 \mathrm{~d}$, the migration rate of chloride ions in FA-SG coral mortar was slower than that in coral mortar. 
TABLE 5: Chlorine ion content of mortar samples at $28 \mathrm{~d}$ (wt.\%).

\begin{tabular}{|c|c|c|c|c|}
\hline & $\mathrm{CCS}+\mathrm{DI}-\mathrm{W}$ & $\mathrm{CCS}+\mathrm{H}-\mathrm{S}$ & CFSCS + DI-W & $\mathrm{CFSCS}+\mathrm{H}-\mathrm{S}$ \\
\hline Chloride ion content & 0.0166 & 0.0278 & 0.0142 & 0.027 \\
\hline Curing coefficient $(L)$ & \multicolumn{2}{|c|}{0.403} & \multicolumn{2}{|c|}{0.474} \\
\hline
\end{tabular}

CCS: coral mortar; CFSCS: coral mortar with 15\% fly ash and 15\% slag; DI-W: deionized water; H-S: nitric acid solution.

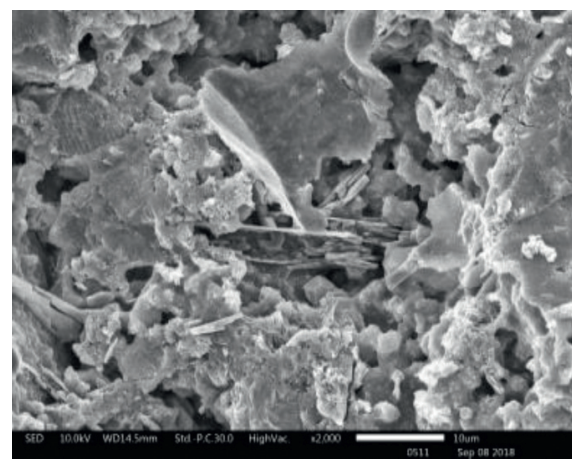

(a)

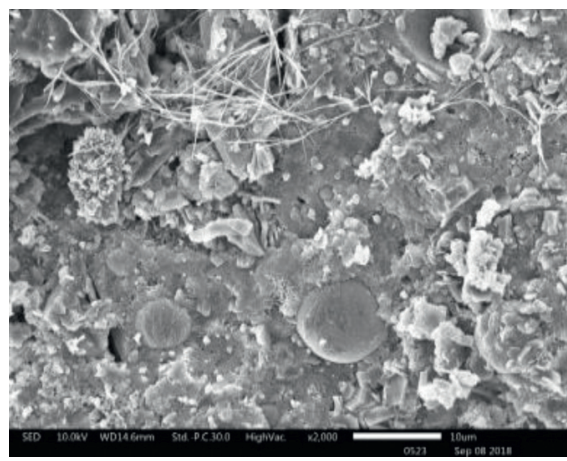

(c)

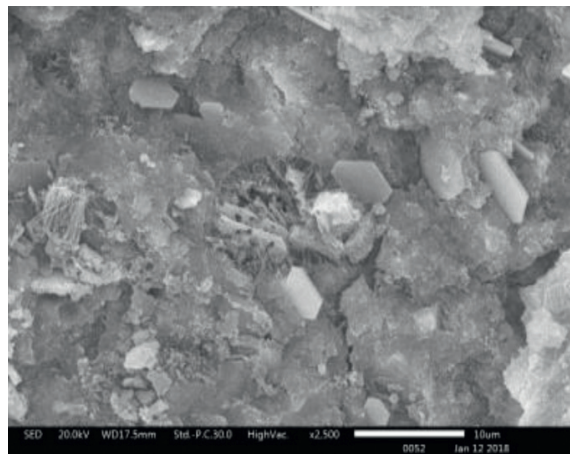

(e)

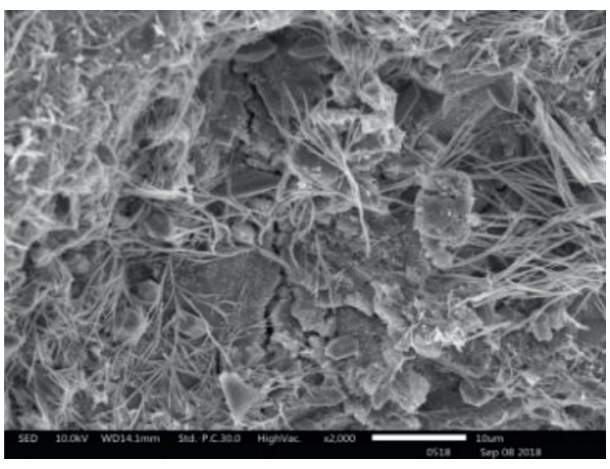

(b)

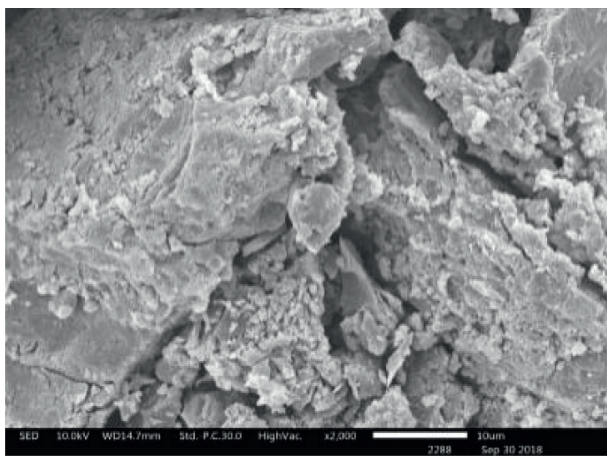

(d)

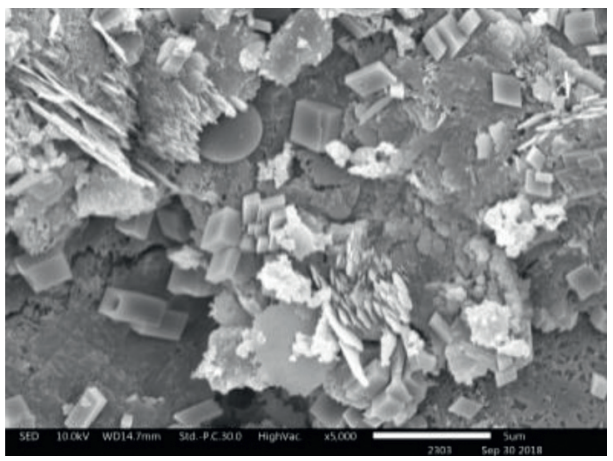

(f)

FIGURE 7: SEM images of mortar samples at 7 and 28 d. CSS: standard mortar; CCS: coral mortar; CFSCS: coral mortar with $15 \%$ fly ash and $15 \%$ slag.

This can be explained by the fact that the filling effect and the immobilizing chloride ions of fly ash and slag made it more difficult for chloride ions to migrate in the mortar.

3.7. XRD Analysis. Figure 10 shows the XRD patterns of three groups of mortar samples at different curing times. The main mineral phases were $\mathrm{C}_{3} \mathrm{~S}$, ettringite, $\mathrm{Ca}(\mathrm{OH})_{2}$, and quartz. From the XRD analysis of the mortar samples at $7 \mathrm{~d}$, it can be seen that the values of the $\mathrm{Ca}(\mathrm{OH})_{2}$ peak were almost the same. However, in the three samples at $28 \mathrm{~d}$, the $\mathrm{Ca}(\mathrm{OH})_{2}$ peak of FA-SG coral mortar was significantly lower than that of the other two samples. This was because the pozzolanic reaction of mineral admixtures consumed part of $\mathrm{Ca}(\mathrm{OH})_{2}$. These data also supported the results of SEM analysis, indicating that the incorporation of mineral admixtures helped to absorb $\mathrm{Ca}(\mathrm{OH})_{2}$ and promoted the formation of hydration gel. As the main component of coral 


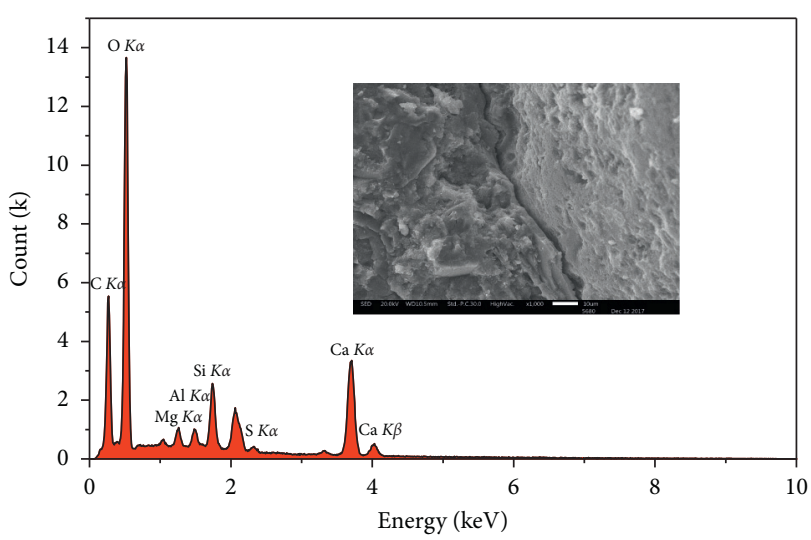

(a)

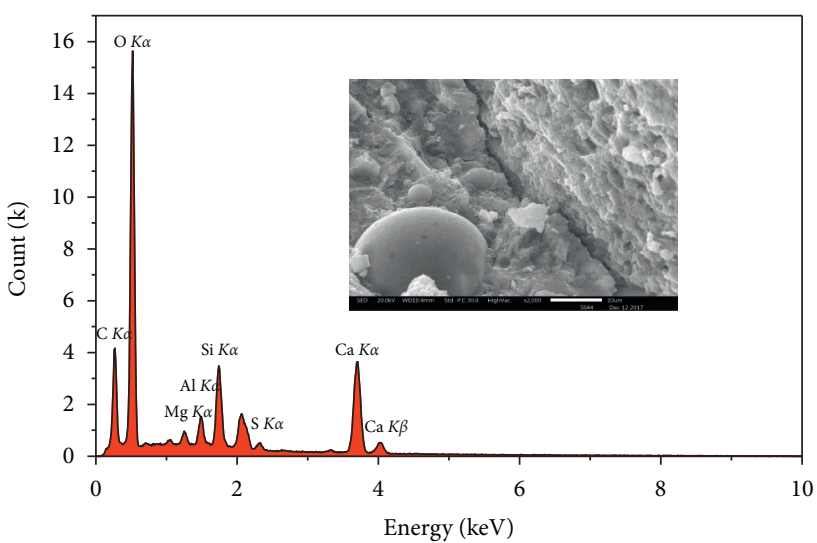

(b)

FIGURE 8: EDS results of the interface of mortar samples with and without mineral admixture at $7 \mathrm{~d}$ : (a) CCS and (b) CFSCS. CCS: coral mortar; CFSCS: coral mortar with $15 \%$ fly ash and $15 \%$ slag.

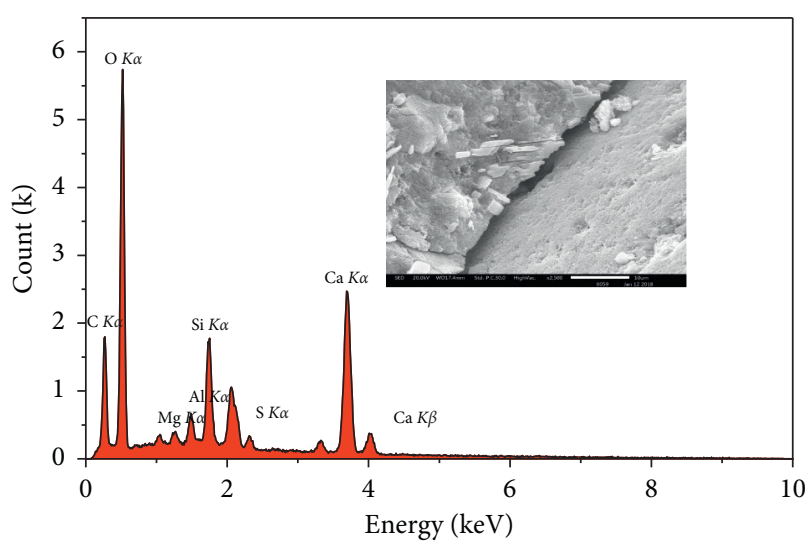

(a)

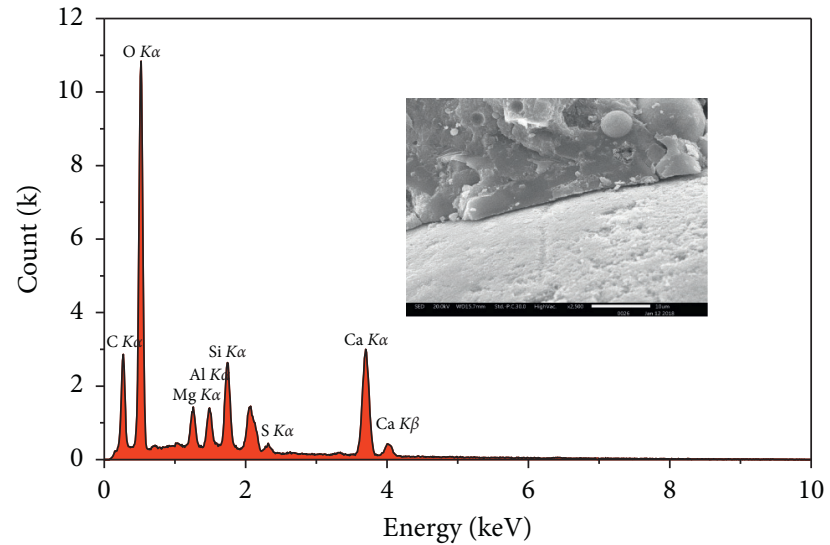

(b)

FIGURE 9: EDS results of the interface of mortar samples with and without mineral admixture at $28 \mathrm{~d}$ : (a) CCS and (b) CFSCS. CCS: coral mortar; CFSCS: coral mortar with $15 \%$ fly ash and $15 \%$ slag.

TABLE 6: EDS analysis of mortar samples at $7 \mathrm{~d}$.

\begin{tabular}{lcccc}
\hline \multirow{2}{*}{ Element } & \multicolumn{2}{c}{ CFSCS at 7 d } & \multicolumn{2}{c}{ CCS at 7 d } \\
& Weight of ITZ (\%) & Weight of CM (\%) & Weight of ITZ (\%) & Weight of CM (\%) \\
\hline $\mathrm{Ca}$ & 26.12 & 27.51 & 25.38 & 35.56 \\
$\mathrm{Cl}$ & 0.09 & 0.04 & 0.08 & 0.04 \\
$\mathrm{Mg}$ & 0.83 & 1.06 & 1.06 & 0.51 \\
\hline
\end{tabular}

CCS: coral mortar; CFSCS: coral mortar with 15\% fly ash and 15\% slag; ITZ: interface transition zone; CM: matrix position.

TABLE 7: EDS analysis of mortar samples at $28 \mathrm{~d}$.

\begin{tabular}{lcccc}
\hline \multirow{2}{*}{ Element } & \multicolumn{2}{c}{ CFSCS at 28 d } & \multicolumn{2}{c}{ CCS at 28d } \\
& Weight of ITZ (\%) & Weight of CM (\%) & Weight of ITZ (\%) & 35.18 \\
$\mathrm{Ca}$ & 27.63 & 33.36 & 0.07 & 34.69 \\
$\mathrm{Cl}$ & 0.08 & 0.05 & 0.55 & 0.06 \\
$\mathrm{Mg}$ & 2.25 & 0.8 & 0.5 \\
\hline
\end{tabular}

CCS: coral mortar; CFSCS: coral mortar with $15 \%$ fly ash and $15 \%$ slag; ITZ: interface transition zone; CM: matrix position. 


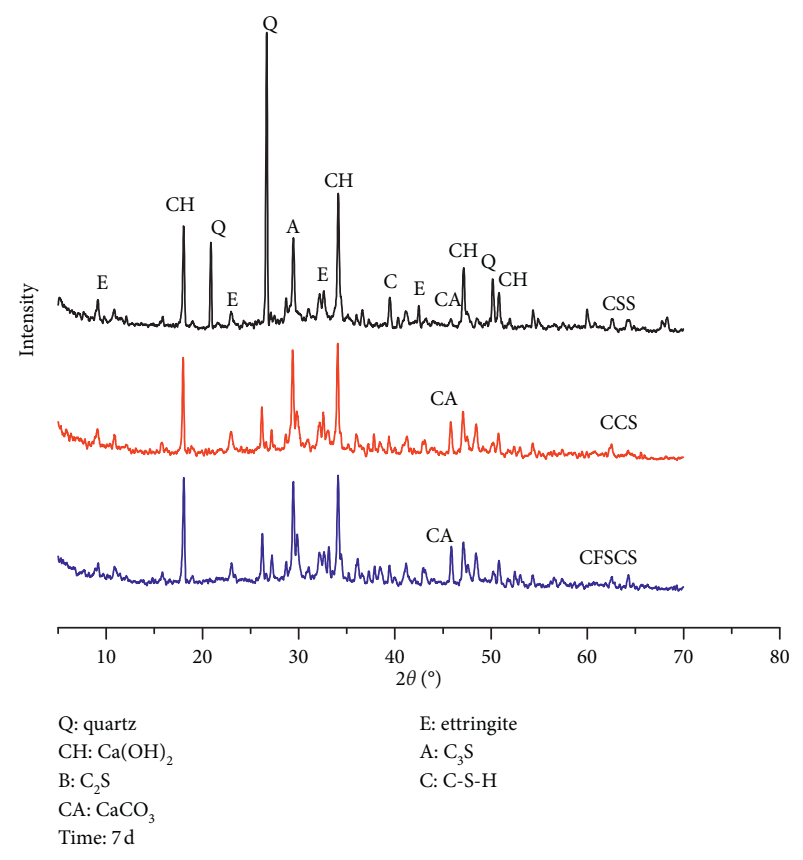

(a)
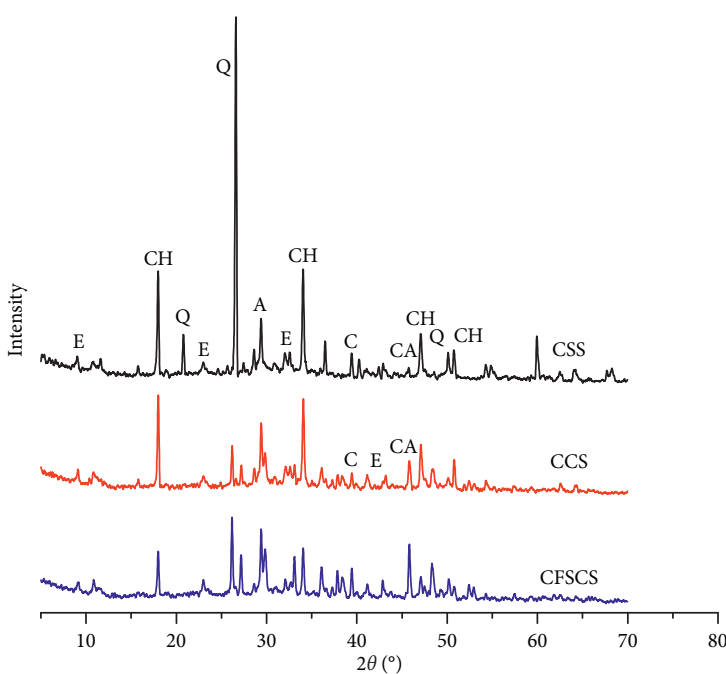

$$
\begin{array}{ll}
\text { Q: quartz } & \text { E: ettringite } \\
\mathrm{CH}: \mathrm{Ca}(\mathrm{OH})_{2} & \text { A: } \mathrm{C}_{3} \mathrm{~S} \\
\text { B: } \mathrm{C}_{2} \mathrm{~S} & \text { C: } \mathrm{C}-\mathrm{S}-\mathrm{H}
\end{array}
$$$$
\text { CA: } \mathrm{CaCO}_{3}
$$$$
\text { Time: } 28 \mathrm{~d}
$$

(b)

FIGURE 10: XRD analysis of mortar samples at (a) $7 \mathrm{~d}$ and (b) $28 \mathrm{~d}$. CSS: standard mortar; CCS: coral mortar; CFSCS: coral mortar with 15\% fly ash and 15\% slag.

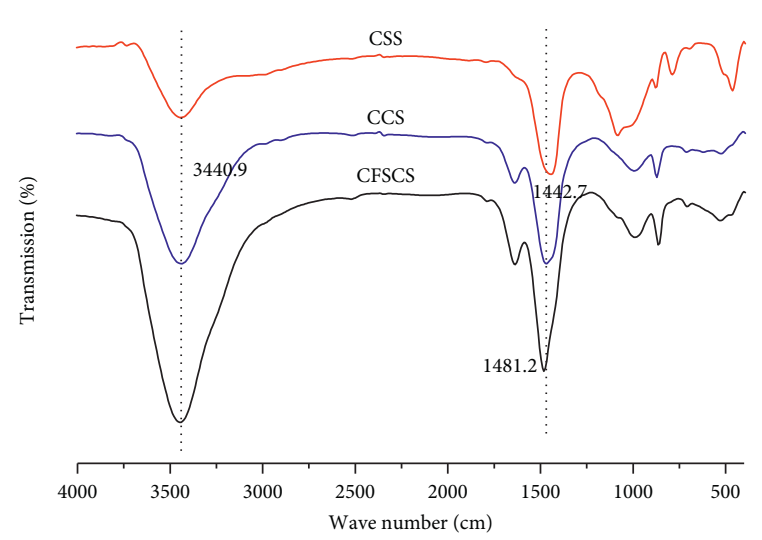

(a)

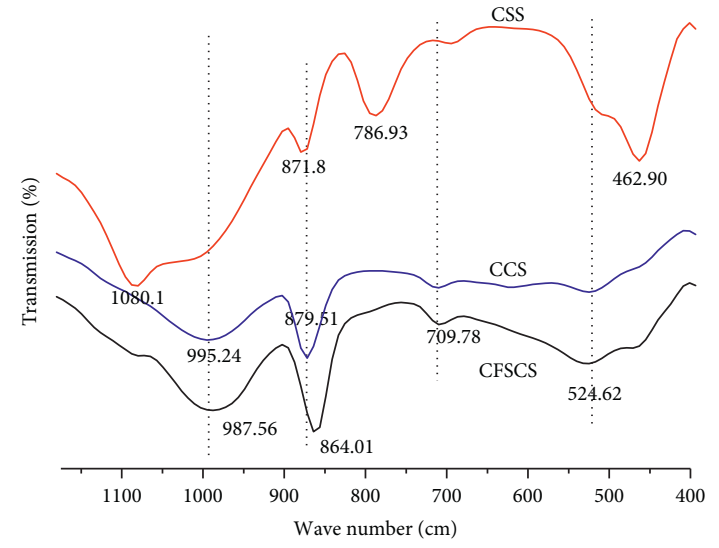

(b)

FIGURE 11: (a) FTIR spectra of mortar samples at $7 \mathrm{~d}$. (b) A larger version of part of the curve in (a). CSS: standard mortar; CCS: coral mortar; CFSCS: coral mortar with $15 \%$ fly ash and $15 \%$ slag.

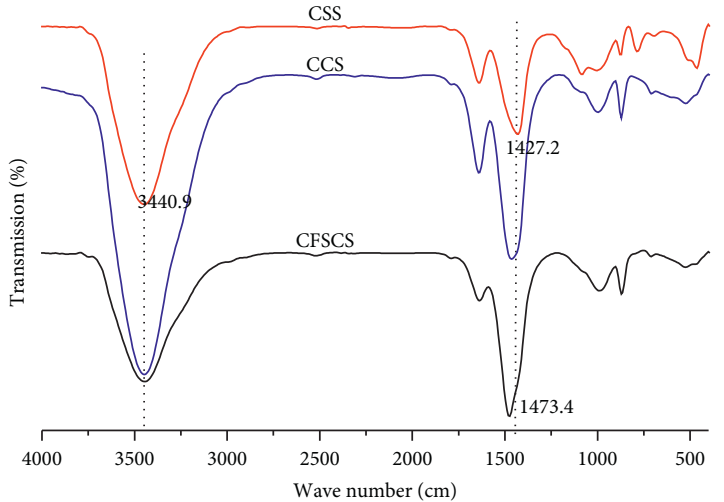

(a)

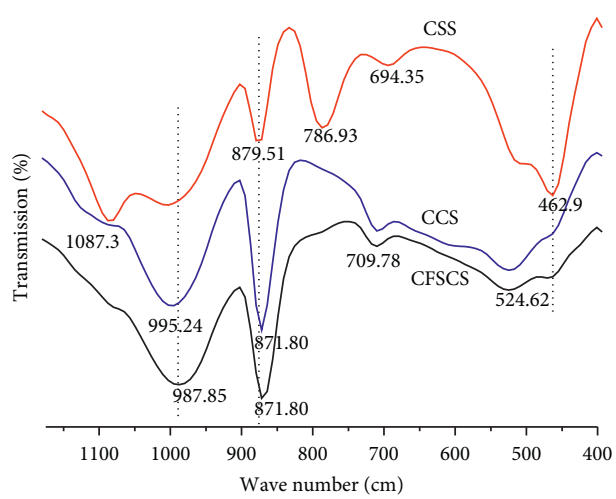

(b)

Figure 12: (a) FTIR spectra of mortar samples at $28 \mathrm{~d}$. (b) A larger version of part of the curve in (a). CSS: standard mortar; CCS: coral mortar; CFSCS: coral mortar with $15 \%$ fly ash and $15 \%$ slag. 
sand is calcium carbonate, the content of calcium carbonate in coral mortar is much higher compared to that in standard sand.

3.8. FTIR Analysis. Figures 11 and 12 show the characteristic infrared spectra of the three samples at $7 \mathrm{~d}$ and $28 \mathrm{~d}$. The peak at $3400 \mathrm{~cm}^{-1}$ corresponded to the stretching vibration of the $\mathrm{O}-\mathrm{H}$ bond of $\mathrm{C}-\mathrm{S}-\mathrm{H}$ gel crystallization water. The absorption peak at $\sim 1458.1 \mathrm{~cm}^{-1}$ was attributed to the bending vibration of $\mathrm{CO}_{3}{ }^{2-}$. The characteristic absorption peak of coral mortar at $\sim 1458.1 \mathrm{~cm}^{-1}$ was more obvious than that of standard mortar, which was due to the large number of coral bones and shellfish with high $\mathrm{CaCO}_{3}$ content. The stretching vibration absorption band of $\mathrm{SiO}_{4}{ }^{2-}$ of C-S-H gel was located at $1175 \sim 860 \mathrm{~cm}^{-1}$, and the stretching vibration of the Si-O bond was at $970-984 \mathrm{~cm}^{-1}$. The two bands at $\sim 460 \mathrm{~cm}^{-1}$ and $\sim 523 \mathrm{~cm}^{-1}$ corresponded to the bending vibration of the Si-O bond. The difference in relative intensities of the absorption peak at $871 \mathrm{~cm}^{-1}$ indicated that the content of C-S-H gel in coral mortar was higher than that in standard mortar [32]. This was because $\mathrm{Ca}^{2+}$ and $\mathrm{Mg}^{2+}$ ions from coral sand continuously participated in hydration reaction, generating more hydration products $[33,34]$. The difference between spectral patterns in the fingerprint area was mainly caused by the small amount of organic matter such as microorganisms in coral sand.

\section{Conclusions}

The main results of this study are summarized as follows:

(1) The mechanical strength of coral mortar was lower than that of standard mortar. The mechanical properties of coral mortar could be improved by mineral admixtures, which improved the microstructure and interfacial transition zone. The compressive strength of coral mortar modified by the mineral admixture at $28 \mathrm{~d}$ was $2.08 \%$ higher than that of standard mortar.

(2) Due to the uneven surface of coral sand, it can be closely meshed with hardened cement paste, thus limiting the shrinkage of the cement matrix. Therefore, the volume stability of coral mortar was better than that of standard mortar.

(3) $\mathrm{Ca}^{2+}$ and $\mathrm{Mg}^{2+}$ ions, continuously released from coral sand, participated in the hydration reaction of cement. This was conducive to the generation of more hydration products, which improved the mechanical properties and shrinkage resistance of the mortar.

\section{Data Availability}

The data used to support the findings of this study are available from the corresponding author upon request.

\section{Conflicts of Interest}

The authors declare that they have no conflicts of interest.

\section{Acknowledgments}

The authors would like to express their appreciation to the financial supports from the "13th Five-Year" Plan for Key Research and Development of China (No. 2017YFB0310100), the Major Special Research and Development Program of Hubei Province (No. 2018AAA001), and the National Natural Science Foundation of China (Grant No. 51908434).

\section{References}

[1] U. Monica and A. Murthy, "Sand mining: curbing the evil to the environment through sustainable substitution and legislative action," Oida International Journal of Sustainable Development, vol. 7, no. 3, pp. 17-26, 2014.

[2] P. Nanthagopalan and M. Santhanam, "Fresh and hardened properties of self-compacting concrete produced with manufactured sand," Cement and Concrete Composites, vol. 33, no. 3, pp. 353-358, 2011.

[3] S. Sreebha and D. Padmalal, "Environmental impact assessment of sand mining from the small catchment rivers in the southwestern coast of India: a case study," Environmental Management, vol. 47, no. 1, pp. 130-140, 2011.

[4] W. H. Langer, "Geologic and societal factors affecting the international oceanic transport of aggregate," Nonrenewable Resources, vol. 4, no. 4, pp. 303-309, 1995.

[5] J. Tang, H. Cheng, Q. Zhang, W. Chen, and Q. Li, "Development of properties and microstructure of concrete with coral reef sand under sulphate attack and drying-wetting cycles," Construction and Building Materials, vol. 165, pp. 647-654, 2018.

[6] W. Jie, P. Feng, T. Hao et al., "Axial compressive behavior of seawater coral aggregate concrete-filled FRP tubes," Construction \& Building Materials, vol. 147, pp. 272-285, 2017.

[7] P. Hughes, D. Fairhurst, I. Sherrington et al., "Microscopic examination of a new mechanism for accelerated degradation of synthetic fibre reinforced marine concrete," Construction and Building Materials, vol. 41, no. 2, pp. 498-504, 2013.

[8] O. E. Frihy, M. A. El Ganaini, W. R. El Sayed, and M. M. Iskander, "The role of fringing coral reef in beach protection of Hurghada, Gulf of Suez, Red Sea of Egypt," Ecological Engineering, vol. 22, no. 1, pp. 17-25, 2004.

[9] O. E. Iskander, A. N. Hassan, W. R. El Sayed, M. M. Iskander, and M. Y. Sherif, "A review of methods for constructing coastal recreational facilities in Egypt (Red Sea)," Ecological Engineering, vol. 27, no. 1, pp. 1-12, 2006.

[10] T. Shishido, "'Wakayama Marine City project in Wakanoura Bay-utilization of the coastal zone through construction of artificial island," Marine Pollution Bulletin, vol. 23, pp. 389395, 1991.

[11] D. Bo, H. Yu, H. Ma, Y. Tan, R. Mi, and X. Dou, "Chloride diffusion study of coral concrete in a marine environment," Construction \& Building Materials, vol. 123, pp. 47-58, 2016.

[12] R.-J. Mi, H.-F. Yu, H. Y. Ma et al., "Study on the mechanical property of coral concrete," Ocean Engineering, vol. 34, no. 4, pp. 48-54, 2016.

[13] R. Wang, K.-F. Yu, Y.-H. Wang et al., "The diagenesis of coral reefs," Advances in Earth Science, vol. 32, no. 3, pp. 221-233, 2017, in Chinese.

[14] L.-K. Sang and C.-Q. Ma, Petrology, Geological Publishing House, Wuhan, China, 2nd edition, 2009.

[15] S. A. Abo-El-Enein, A. H. Ali, F. N. Talkhan, H. A. AbdelGawwad et al., "Utilization of microbial induced calcite 
precipitation for sand consolidation and mortar crack remediation," HBRC Journal, vol. 8, no. 3, pp. 185-192, 2012.

[16] P. A. Howdyshell, The Use of Coral as Aggregate and Cement Concrete Structures, Army Construction Engineering Research Laboratory, Champaign, IL, USA, 1974.

[17] Q. Wang, P. Li, Y. Tian, W. Chen, and C. Su, "Mechanical properties and microstructure of Portland cement concrete prepared with coral reef sand," Journal of Wuhan University of Technology-Mater. Sci. Ed., vol. 31, no. 5, pp. 996-1001, 2016.

[18] Y. F. Cui, J. H. Liu, and J. Liang, "Study of performance and microstructure of sea sand on ripe pile concrete," in International Conference on Electronics (ICECC), Ningbo, China, September 2011.

[19] S.-J. Fan and B.-M. Wang, "Effect of air entraining agents on the long-term drying shrinkage of glazed hollow beads thermal insulation mortar," Journal of Building Materials, vol. 19, no. 1, pp. 1-7, 2016, in Chinese.

[20] J.-X. Gong and F.-J. Jiang, "Study on properties of concrete with mineral admixtures under chloride environment by electrochemical impedance spectroscopy," Concrete, vol. 7, no. 7, pp. 42-47, 2014.

[21] Z.-Z. Xu, "Electrochemical progress of cement concrete-theory of ac impedance spectroscopy," Journal of the Chinese Ceramic Society, vol. 22, no. 2, pp. 173-180, 1994, in Chinese.

[22] P. Gu, Z. Xu, P. Xie, and J. J. Beaudoin, "Application of A.C. impedance techniques in studies of porous cementitious materials," Cement and Concrete Research, vol. 23, no. 3, pp. 531-540, 1993.

[23] P. Xie, P. Gu, Y. Fu, and J. J. Beaudoin, "A.C. impedance phenomena in hydrating cement systems: detectability of the high frequency arc," Cement and Concrete Research, vol. 24, no. 1, pp. 92-94, 1994.

[24] T. Zhang, C. R. Cheeseman, and L. J. Vandeperre, "Development of low $\mathrm{pH}$ cement systems forming magnesium silicate hydrate (M-S-H)," Cement and Concrete Research, vol. 41, no. 4, pp. 439-442, 2011.

[25] Y. Wang, Y. F. Chen, Y. Lu, H. F. Zhang, and Z. G. Sun, "Compressive strength changing law of oil well cement paste under corporate corrosion of $\mathrm{HCO}_{3}{ }^{-}$and $\mathrm{SO}_{4}{ }^{2-}$.," Applied Mechanics and Materials, vol. 229-231, pp. 95-99, 2012.

[26] D. Foti, M. Lerna, M. Sabbà, and V. Vacca, "Mechanical characteristics and water absorption properties of blast-furnace slag concretes with fly ashes or microsilica additions," Applied Sciences, vol. 9, no. 7, p. 1279, 2019.

[27] D. Vacca and D. Cavallo, "Mechanical behavior of concretes made with non-conventional organic origin calcareous aggregates," Construction and Building Materials, vol. 179, pp. 100-106, 2018.

[28] D. Foti, "Innovative techniques for concrete reinforcement with polymers," Construction and Building Materials, vol. 112, pp. 202-209, 2016.

[29] T. Luping and L.-O. Nilsson, "Chloride binding capacity and binding isotherms of OPC pastes and mortars," Cement \& Concrete Research, vol. 23, no. 2, pp. 247-253, 1993.

[30] M. D. A. Thomas and P. B. Bamforth, "Modelling chloride diffusion in concrete," Cement and Concrete Research, vol. 29, no. 4, pp. 487-495, 1999.

[31] R. Li, G. Wu, L. Jiang, and D. Sun, "Characterization of multiscale porous structure of fly ash/phosphate geopolymer hollow sphere structures: from submillimeter to nano-scale," Micron, vol. 68, pp. 54-58, 2015.

[32] M. Li, X. Zhu, A. Mukherjee, M. Huang, and V. Achal, "Biomineralization in metakaolin modified cement mortar to improve its strength with lowered cement content," Journal of Hazardous Materials, vol. 329, pp. 178-184, 2017.

[33] D. Bonen, "Composition and appearance of magnesium silicate hydrate and its relation to deterioration of cement-based materials," Journal of the American Ceramic Society, vol. 75, no. 10, pp. 2904-2906, 1992.

[34] Z.-H. Shui and H.-W. Wan, "Distribution characteristics of elements in ITZ between aggregate and cement in concrete," Journal of Wuhan University of Technology-Mater. Sci. Ed., vol. 24, no. 5, pp. 22-25, 2002. 